\title{
Implementasi Deteksi Serangan Epilepsi dari Data Rekaman EEG Menggunakan Weighted Permutation Entropy dan Support Vector Machine
}

\author{
Lophita Y Napitupulu, Nanik Suciati, Dini Adni Navastara \\ Departemen Teknik Informatika, Fakultas Teknologi Informasi, Institut Teknologi Sepuluh Nopember (ITS) \\ e-mail: nanik@if.its.ac.id
}

\begin{abstract}
Abstrak-Epilepsi merupakan gangguan neurologis jangka panjang yang ditandai dengan serangan-serangan epileptik. Serangan epileptik dapat terjadi dalam waktu singkat hingga guncangan kuat dalam waktu yang lama. Epilepsi adalah penyakit yang cenderung terjadi secara berulang dan tidak dapat disembuhkan, namun serangan-serangan epileptik yang terjadi dapat dikontrol melalui pengobatan. Pada studi ini, data rekaman electroencephalogram (EEG) dibagi menjadi beberapa window menggunakan segmentasi atau dekomposisi. Proses selanjutnya adalah mengekstraksi setiap window dengan menggunakan Weighted Permutation Entropy yang menghasilkan satu fitur setiap window. Uji coba fitur menggunakan k-fold crossvalidation dengan membagi data menjadi data training dan data testing. Selanjutnya data diklasifikasi menggunakan Support Vector Machine. Data rekaman EEG yang digunakan untuk pengujian ini berasal dari "Klinik für Epileptologie, Universität Bonn" yang diperoleh secara online yang berjumlah 500 data. Data ini terdiri dari serangan epilepsi (set S) dan bukan serangan epilepsi (set Z, N, O, F) yang masing-masing set terdiri dari 100 data. Set $Z$ direkam dari lima orang sehat dengan mata tertutup dan set $O$ direkam dari lima orang sehat mata terbuka. Set $F$ direkam dari penderita epilepsi yang tidak mengalami serangan di hippocampal formation, set $\mathrm{N}$ direkam dari penderita epilepsi yang tidak mengalami sernagan di epileptogenic zone, dan set $S$ direkam dari penderita epilepsi ketika terjadi serangan di epileptogenic zone. Uji coba dilakukan pada data set $\mathbf{S}$ digabung dengan setiap set lain. Sehingga data yang digunakan sebanyak 200 data rekaman EEG untuk setiap uji coba. Berdasarkan uji coba, metode tersebut menghasilkan akurasi rata-rata sebesar $\mathbf{9 1 , 8 8 \%}$.
\end{abstract}

Kata Kunci-Epilepsi, EEG, Weighted Permutation Entropy, Support Vector Machine.

\section{PENDAHULUAN}

$\mathrm{E}$ PILEPSI adalah gangguan neurologis jangka panjang yang ditandai dengan adanya serangan-serangan epileptik [1]. Serangan epileptik bisa bermacam-macam mulai dari serangan singkat dan hampir tidak terdeteksi hingga guncangan kuat dalam waktu yang lama. Epilepsi cenderung terjadi secara berulang dan tidak ada penyebab yang mendasari secara langsung. Dalam kebanyakan kasus, penyebab epilepsi ini tidak dapat diketahui, walaupun beberapa orang menderita epilepsi karena cedera dari aktivitas sel saraf kortikal yang berlebihan dan tidak normal di dalam otak. Epilepsi tidak bisa disembuhkan, namun serangan-serangan dapat dikontrol melalui pengobatan pada sekitar 70\% kasus [2].

Elektrosefalografi (EEG) adalah rekaman aktivitas listrik sepanjang kulit kepala yang dihasilkan oleh penembakan neuron dalam otak. EEG mengacu pada rekaman spontan listrik aktivitas otak selama periode tertentu. Dalam dunia neurologi, diagnosis menggunakan EEG digunakan untuk mendeteksi penyakit epilepsi. Pemeriksaan EEG dapat membantu memberikan gambaran aktivitas otak yang menunjukkan peningkatan risiko terjadinya serangan epilepsi.

Pemantauan serangan epilepsi atau kejang secara tradisional dilakukan oleh neurofisiolog dengan meninjau dan menganalisis data rekaman EEG. Namun, menemukan serangan epilepsi dalam rekaman EEG akan memakan waktu dan melelahkan. Pada penelitian sebelumnya [3], melibatkan 4 ahli untuk menemukan serangan epilepsi dalam 8 jam rekaman EEG. Setiap ahli memberikan hasil pemantauan yang sedikit berbeda-beda. Kejang yang dialami penderita dapat menyebabkan hilangnya kesadaran, gangguan pada perasa dan fungsi kognitif. Penderita epilepsi juga cenderung mengalami masalah psikologis dan tingkat kematian dini tiga kali lebih tinggi [4]. Untuk mengontrol serangan-serangan yang terjadi, maka perlu dilakukan pengobatan yang cepat sehingga penderita tidak mengalami guncangan yang merugikan dirinya sendiri.

Seiring berkembangya teknologi yang dapat mempercepat pekerjaan manusia, penggunaan teknologi di bidang kesehatan pun sudah dilakukan. Penerapan teknologi untuk mendeteksi berbagai penyakit termasuk penyakit epilepsi telah dilakukan. Mengingat perlunya mendeteksi serangan epilepsi dan pengobatan secara cepat, beberapa penelitian telah dilakukan. Penelitian yang dilakukan menggunakan metode berbeda-beda, diantaranya menggunakan algoritma permutation entropy sebagai ekstraksi fitur dan Support Vector Machine sebagai metode klasifikasi yang menghasilkan akurasi rata-rata sebesar $86,10 \%$ [5] dan menggunakan algoritma time frequency analysis sebagai ekstraksi fitur dan Artificial Neural Network sebagai metode klasifikasi yang menghasilkan akurasi rata-rata sebesar $89,00 \%$ [6].

Pada studi ini dilakukan pengembangan teknologi untuk mendeteksi serangan epilepsi menggunakan Weighted Permutation Entropy (WPE) dan Support Vector Machine (SVM). WPE adalah adalah modifikasi Permutation Entropy yang mengukur kompleksitas dan ketidakteraturan time series 
dengan menggabungkan pola permutasi dan amplitudo setiap sampel. Proses pengembangan sistem dilakukan dengan beberapa tahap yaitu, segmentation/pre-processing data, ekstraksi fitur menggunakan WPE, dan klasifikasi menggunakan SVM. Data masukan awal yang digunakan adalah data rekaman EEG otak manusia yang direkam dari manusia normal, penderita yang tidak mengalami serangan epilepsi dan penderita yang sedang mengalami serangan epilepsi. Studi ini diharapkan dapat memberikan hasil deteksi serangan epilepsi yang baik.

\section{METODOLOGI}

Untuk melakukan deteksi serangan epilepsi terdapat tiga proses yaitu segmentation atau decomposition, ekstraksi fitur, dan klasifikasi. Diagram alir tahapan utama sistem ditunjukkan pada Gambar 1.

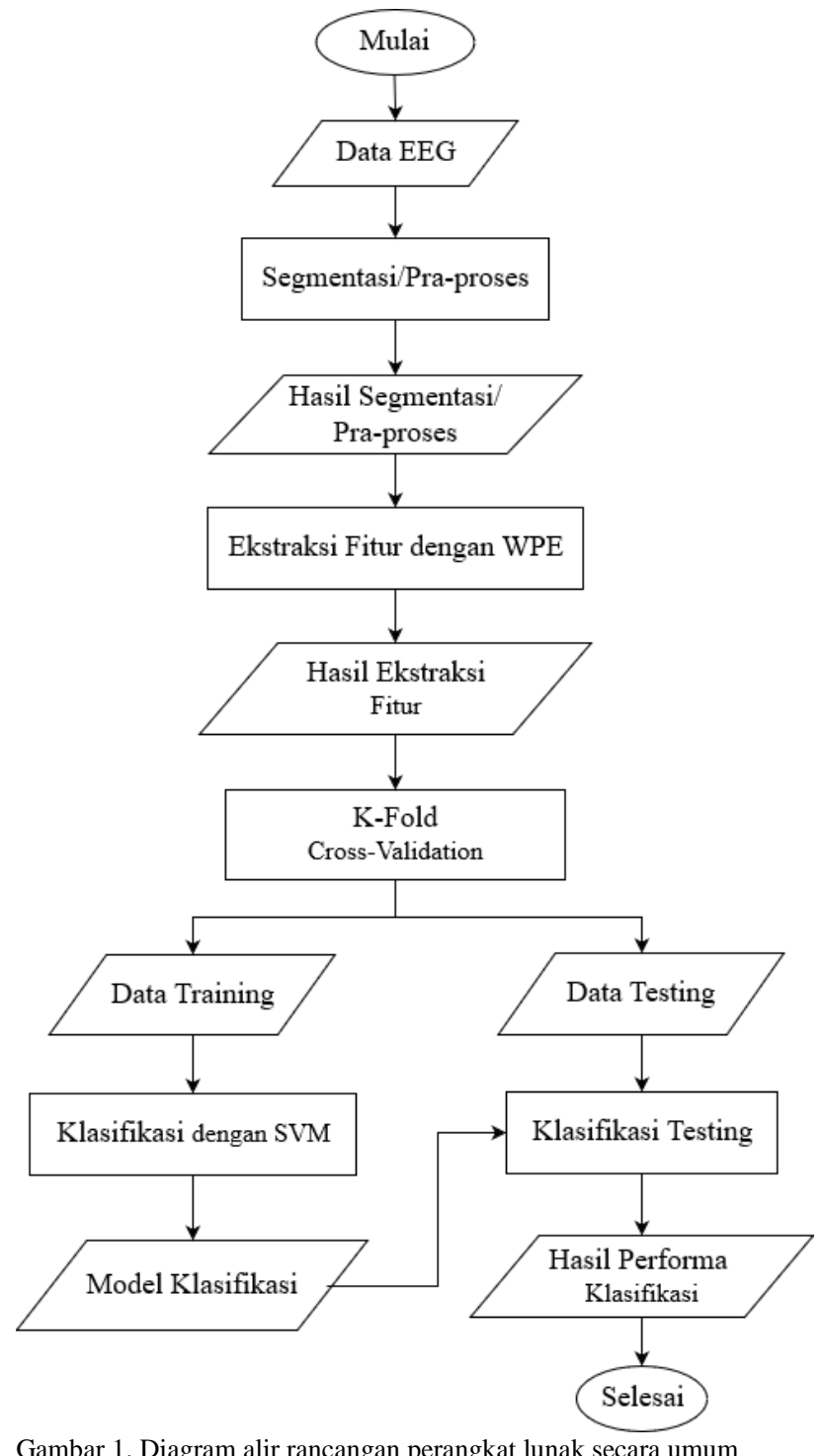

Gambar 1. Diagram alir rancangan perangkat lunak secara umum

\section{A. Tahap Segmentation}

Segmentation atau bisa juga disebut dengan segmentasi merupakan metode untuk membagi data menjadi beberapa window. Pada perangkat lunak ini, jenis segmentasi yang akan digunakan adalah constant segmentation, dimana data akan dibagi menjadi beberapa window dengan panjang data di setiap window adalah sama. Pada perangkat lunak ini, proses segmentasi data akan dijadikan sebagai skenario uji coba, dimana data akan dibagi ke dalam window secara nonoverlapping dan overlapping.

Pada tahap ini data masukan yang digunakan adalah data EEG yang diperoleh dari website. Setiap data EEG memiliki panjang 4097 nilai dan akan dibagi ke dalam beberapa window dengan panjang masing-masing 64 nilai. Untuk segmentasi secara non-overlapping, data akan bergeser ke depan sebesar 64 nilai sehingga tidak ada tumpang tindih nilai antar window.

Segmentation dilakukan untuk membagi data menjadi beberapa window dengan panjang yang sama. Pada perangkat lunak ini, proses segmentasi data akan dijadikan sebagai skenario uji coba, dimana data akan dibagi ke dalam window secara non-overlapping dan overlapping. Data masukan yang digunakan adalah data EEG yang diperoleh dari website. Setiap data EEG memiliki panjang 4097 nilai dan akan dibagi ke dalam beberapa window dengan panjang masing-masing 64 nilai.

Untuk segmentasi secara non-overlapping, data akan bergeser ke depan sebesar 64 nilai sehingga tidak ada tumpang tindih nilai antar window. Untuk segmentasi secara overlapping data akan bergeser ke depan sebesar 32 nilai, sehingga sebesar 32 nilai akan tumpang tindih antar window.

Untuk segmentasi secara overlapping data akan bergeser ke depan sebesar 32 nilai, sehingga sebesar 32 nilai akan tumpang tindih antar window. Oleh karena itu, setiap data EEG yang disegmentasi secara non-overlapping akan memiliki 64 window dan data EEG yang disegmentasi secara overlapping akan memiliki 127 window.

\section{B. Tahap Decomposition}

Discrete Wavelet Transform (DWT) merupakan metode untuk mendekomposisi sinyal menjadi dua bagian yang memiliki panjang data yang sama pada tiap levelnya. Dua bagian ini terdiri dari dua band frekuensi yang berbeda yang dipisahkan oleh dua jenis filter yaitu highp ass filter dan lowpass filter. DWT melakukan dekomposisi pada mother wavelet atau biasa disebut sinyal utama sehingga lowpass filter menghasilkan koefisien aproksimasi dan highpass filter menghasilkan koefisien detail. Untuk dekomposisi level selanjutnya, koefisien aproksimasi akan berfungsi sebagai mother wavelet.

Pada tahap ini data masukan yang digunakan adalah data EEG yang berfungsi sebagai mother wavelet. Data EEG ini berada pada rentang $0-60 \mathrm{~Hz}$ dan data ini akan dibagi sesuai band frekuensi otak manusia yaitu, delta, theta, alpha, beta, dan gamma. Maka dapat disimpulkan bahwa satu data EEG akan didekomposisi ke dalam 5 window sesuai band frekuensi yaitu, 0-4 Hz, 4-8 Hz, 8-15 Hz, 15-30 Hz, dan 30-60 Hz.

Pada level pertama satu data EEG berfungsi sebagai mother wavelet yang menghasilkan koefisien aproksimasi disingkat cA1 $(0-30 \mathrm{~Hz})$ dan koefisien detail disingkat cD1 $(30-60 \mathrm{~Hz})$. Pada level dua, koefisien aproksimasi dari level pertama akan 
berfungsi sebagai mother wavelet dan akan menghasilkan koefisien aproksimasi cA2 $(0-15 \mathrm{~Hz})$ dan koefisien detail cD2 $(15-30 \mathrm{~Hz})$ begitu seterusnya sampai level empat. Sehingga di hasil akhir akan diperoleh 5 window yaitu window satu berisi data $\mathrm{cA} 4$, window dua berisi data $\mathrm{cD} 4$, window tiga berisi data $\mathrm{cD} 3$, window empat berisi data $\mathrm{cD} 2$, dan window lima berisi data $\mathrm{cD} 1$ yang koresponden terhadap band frekuensi $0-4 \mathrm{~Hz}$, 4-8 Hz, 8-15 Hz, 15-30 Hz, dan 30-60 Hz secara berurutan.

\section{Tahap Ekstraksi Fitur}

Weighted permutation entropy (WPE) pada studi ini bertujuan untuk mengekstraksi fitur data EEG. Metode WPE mengukur kompleksitas dan ketidakteraturan time series dengan membandingkan nilai tetangga dan amplitudo berbeda pada setiap setiap pola permutasi. WPE memperkirakan distribusi entropi pada kelompok permutasi dari sampel waktu dan perubahan pada amplitudonya. Sehingga variasi WPE sebagai fungsi waktu dapat dengan efektif menunjukkan perubahan pada data yang sesungguhnya.

Pada tahap ekstraksi fitur data masukan yang digunakan adalah data window hasil segmentasi atau data window hasil dekomposisi Discrete Wavelet Transform. Setiap data rekaman EEG yang disegmentasi secara non-overlapping memiliki 64 window, sedangkan yang disegmentasi secara overlapping memiliki 127 window, dan yang didekomposisi dengan Discrete Wavelet Transform memiliki 5 window. Setiap data window akan diekstraksi hingga memperoleh satu nilai entropi yang merepresentasikan nilai fitur. Garis besar proses ekstraksi fitur pada setiap data window dapat dilihat pada Gambar 2.

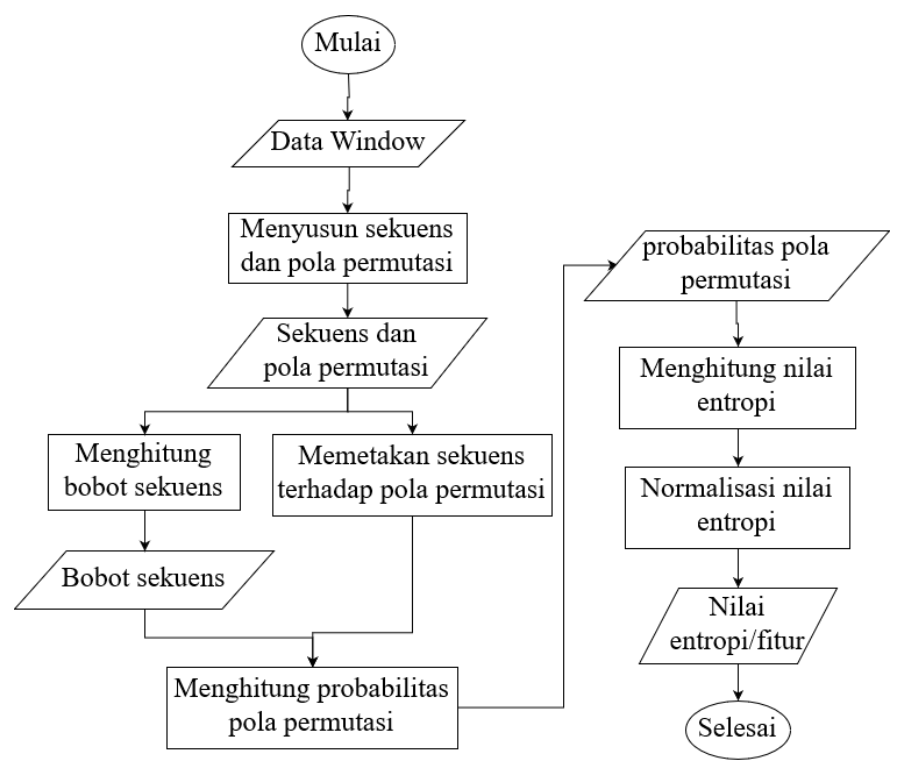

Gambar 2. Diagram alir proses ekstraksi fitur

Proses pertama pada tahapan ekstraksi fitur dimulai dengan membagi data window menjadi beberapa sekuens, yang mana setiap sekuens memiliki panjang sekuens $m$ dan pengambilan nilai dari data window ke dalam setiap sekuens tergantung pada nilai time delay $(\tau)$ seperti dijelaskan sebelumnya dengan menggunakan persamaan (1).

$$
X_{t}=\left\{x_{t}, x_{t+\tau}, x_{t+2 \tau^{\ldots \ldots}}, x_{t+(m-1) \tau}\right\}
$$

Kemudian menyusun pola permutasi yang tergantung pada panjang sekuens. Permutasi adalah susunan unsur-unsur yang berbeda dalam urutan tertentu yang disebut dengan pola permutasi. Dalam hal ini, jumlah unsur ditentukan oleh panjang sekuens. Sehingga dapat disimpulkan bahwa panjang sekuens akan memiliki panjang yang sama dengan panjang pola permutasi. Pada proses pertama dihasilkan sejumlah $\mathrm{N}$ sekuens berdimensi $m$ dan pola permutasi sejumlah permutasi $m(m !)$ berdimensi $m$.

Setiap sekuens memiliki informasi amplitudo yang berbeda dan penting. Sehingga pada proses kedua, nilai informasi amplitudo atau bobot sekuens akan dihitung. Bobot sekuens diperoleh dengan membandingkan nilai sekuens dengan nilai rata-rata sekuens tetangga seperti dijelaskan sebelumnya dengan persamaan (2).

$$
\omega_{j}=\frac{1}{m} \sum_{t=1}^{m}\left(x_{j+l t+1) \tau}-\overline{\mathbf{x}}_{j}\right)^{2}
$$

Nilai rata-rata sekuens diperoleh dengan persamaan (3).

$$
\overline{\mathrm{X}}_{f}=\frac{1}{m} \sum_{\mathrm{t}=1}^{m} \boldsymbol{x}_{f+(\mathrm{t}+1) t}
$$

Selanjutnya setiap sekuens yang terbentuk dipetakan ke pola permutasi yang sesuai. Sehingga sejumlah $\mathrm{N}$ sekuens akan terbagi ke dalam kelompok-kelompok pola permutasi dan setiap sekuens akan berada pada satu pola permutasi. Kemudian probabilitas setiap pola permutasi dihitung dengan menjumlahkan bobot sekuens yang berada dalam kelompok pola permutasi tersebut seperti dijelaskan sebelumnya dengan persamaan (4).

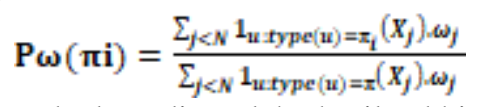

Pada proses kedua diperoleh hasil akhir berupa nilai distribusi probabilitas setiap pola permutasi.

Pada proses terakhir, nilai distribusi probabilitas setiap pola permutasi akan digunakan untuk menghitung nilai entropi. Nilai entropi dihitung dengan menggunakan persamaan (5).

$$
\mathrm{H} \omega(\mathbf{m}, \tau)=-\sum P_{\omega}\left(\pi_{\mathrm{i}}\right) \ln \boldsymbol{P}_{\omega}\left(\mathrm{\pi}_{\mathrm{i}}\right)
$$

Nilai entropi yang diperoleh kemudian dinormalisasi menggunkaan persamaan (6).

$$
\mathrm{H} \omega\left(\mathbf{m}_{,} \tau\right)=-\frac{1}{\ln (m !)} \sum P_{\omega}\left(\pi_{\mathrm{i}}\right) \ln P_{\omega}\left(\pi_{\mathrm{i}}\right)
$$

Nilai normalisasi merupakan nilai akhir dari proses ekstraksi fitur satu data window. Sehingga hasil ekstraksi fitur pada setiap data window merepresentasikan satu nilai fitur. Jumlah fitur setiap data EEG akan sama dengan jumlah window yang diperoleh pada pengolahan awal data rekaman EEG. Setiap data rekaman EEG yang disegmentasi secara non-overlapping akan memiliki 64 window sehingga akan memiliki 64 fitur, sedangkan yang disegmentasi secara overlapping akan memiliki 127 window sehingga akan memiliki 127 fitur, dan yang didekomposisi dengan Discrete Wavelet Transform memiliki 5 window sehingga akan memiliki 5 fitur.

\section{Tahap Klasifikasi}

Support Vector Machine (SVM) merupakan salah satu teknik supervised learning atau pembelajaran terawasi yang paling umum digunakan, karena sangat efektif untuk banyak masalah terutama klasifikasi dua kelas. Klasifikasi dilakukan dengan cara mencari hyperplane terbaik yang memisahkan 
data menjadi dua kelas berbeda.

Data masukan yang digunakan untuk proses klasifikasi adalah data hasil ekstraksi fitur yang telah dikelompokkan menjadi 4 kelompok data yaitu, set $\mathrm{Z}$ dan $\mathrm{S}$, set $\mathrm{O}$ dan $\mathrm{S}$, set $\mathrm{N}$ dan $\mathrm{S}$, serta set $\mathrm{F}$ dan $\mathrm{S}$. Sehingga setiap kelompok data klasifikasi akan terdiri dari 200 data fitur. Jumlah fitur data rekaman EEG berbeda-beda tergantung pada proses pengolahan awal data. Data rekaman EEG yang dengan pengolahan awal segmentasi non-overlapping memiliki 64 fitur, sedangkan yang segmentasi overlapping memiliki 127 fitur, dan dekomposisi dengan Discrete Wavelet Transform memiliki 5 fitur. Data keluaran yang dihasilkan pada tahap klasifikasi ada dua kelas yaitu serangan epilepsi atau bukan serangan epilepsi.

\section{UJI COBA DAN PEMBAHASAN}

\section{A. Data}

Data yang digunakan pada studi ini adalah data rekaman sinyal otak manusia (EEG) yang diunduh dari website milik "Klinik für Epileptologie, Universität Bonn". Pada Studi ini, data yang digunakan adalah kelima set Z, O, N, F, dan S. Setiap set terdiri dari 100 data. Set $S$ adalah satu-satunya set untuk kelas serangan epilepsi sedangkan empat set lainnya adalah kelas bukan serangan epilepsi

\section{B. Uji Coba Kinerja Metode}

Evaluasi dilakukan pada dataset $\mathrm{S}$ terhadap set Z, N, O, dan F. Parameter-parameter yang digunakan yaitu panjang sekuens 4, parameter time delay 1, parameter optimasi C sebesar 100 pada linear SVM, parameter fungsi kernel RBF dengan gamma 2 , nilai $\mathrm{k}$-fold yang digunakan yaitu 10, dan praproses menggunakan segmentasi overlapping. Hasil deteksi serangan epilepsi ditunjukan pada Tabel 1.

\section{KESIMPULAN/RINGKASAN}

Berdasarkan hasil uji coba, penggunaan metode Weighted Permutation Entropy dan Support Vector Machine pada sistem

Tabel 1.

Hasil deteksi serangan epilepsi

\begin{tabular}{cc}
\hline \hline Dataset & Akurasi \\
\hline Z versus S & $97,50 \%$ \\
O versus S & $82,50 \%$ \\
N versus S & $94,00 \%$ \\
F versus S & $93,50 \%$ \\
Rata-rata & $91,88 \%$ \\
\hline
\end{tabular}

diperoleh:

1) Klasifikasi serangan epilepsi dan bukan serangan epilepsi terbaik antara set $\mathrm{S}$ terhadap set $\mathrm{Z}, \mathrm{O}, \mathrm{N}$, dan $\mathrm{F}$ diperoleh dengan pengolahan awal segmentasi overlapping dengan akurasi rata-rata sebesar $91,88 \%$.

2) Implementasi metode Weighted Permutation Entropy dan Support Vector Machine mampu mengklasifikakan aktivitas serangan epilepsi paling baik pada set $\mathrm{S}$ terhadap set $\mathrm{Z}$ dengan akurasi sebesar $97,50 \%$, diikuti oleh set $\mathrm{N}$ dengan akurasi sebesar $94,00 \%$, set $\mathrm{F}$ dengan akurasi sebesar $93,50 \%$, dan terakhir set $\mathrm{O}$ dengan akurasi sebesar $82,50 \%$.

3) Pemilihan parameter panjang sekuens (m) sama dengan 4 menghasilkan rata-rata akurasi terbaik yaitu sebesar $81.4 \%$.

4) Pemilihan parameter time delay sama dengan 1 menghasilkan rata-rata akurasi terbaik yaitu sebesar $81.4 \%$. Semakin besar nilai time delay maka rata-rata akurasi semakin berkurang.

5) Klasifikasi dengan linear SVM menghasilkan rata-rata akurasi terbaik dibandingkan dengan non-linear SVM. Rata-rata akurasi terbaik diperoleh ketika nilai optimasi C sama dengan 100 yaitu sebesar $89,88 \%$.

6) Pemilihan fungsi kernel RBF dengan nilai gamma sama dengan 2 menghasilkan rata-rata akurasi terbaik yaitu sebesar $91,88 \%$.

7) Pemilihan nilai $\mathrm{k}=10$ pada $\mathrm{k}$-fold cross-validation memberikan akurasi terbaik sebesar 91,88\%.

\section{DAFTAR PUSTAKA}

[1] N. S. Tawfik, S. M. Youssef, and M. Kholief, "A hybrid automated detection of epileptic seizures in EEG records," Comput. Electr. Eng., vol. 53, pp. 177-190, Jul. 2016.

[2] W. bahasa Indonesia, "Epilepsi," Wikipedia bahasa Indonesia, 2016.

[3] S. B. Wilson, M. L. Scheuer, C. Plummer, B. Young, and S. Pacia, "Seizure detection: correlation of human experts," Clin. Neurophysiol. Off. J. Int. Fed. Clin. Neurophysiol., vol. 114, no. 11, pp. 2156-2164, Nov. 2003.

[4] Www.who.int, "WHO | Epilepsy," www.who.int, 2017. [Online]. Available: http://www.who.int/mediacentre/factsheets/fs999/en.

[5] N. Nicolaou and J. Georgiou, "Detection of epileptic electroencephalogram based on Permutation Entropy and Support Vector Machines," Expert Syst. Appl., vol. 39, no. 1, pp. 202-209, Jan. 2012.

[6] A. T. Tzallas, M. G. Tsipouras, and D. I. Fotiadis, "The use of timefrequency distributions for epileptic seizure detection in EEG recordings," Conf. Proc. ... Annu. Int. Conf. IEEE Eng. Med. Biol. Soc. IEEE Eng. Med. Biol. Soc. Annu. Conf., vol. 2007, pp. 3-6, 2007. 